\title{
The research on flocculation of Microcystis aeruginosa with combination of microbial flocculant and alum
}

\author{
Guowangchen Liu ${ }^{\mathrm{a}}$, Wenshuang Li ${ }^{\mathrm{b}}$, Cunpeng Duan ${ }^{\mathrm{c}}, \mathrm{Heyu} \mathrm{Lu}^{\mathrm{d}}$, Dan Cui ${ }^{\mathrm{e}}$, \\ Liling Gao ${ }^{f}$, Junchen Dai ${ }^{9}$, Jianchao Hao ${ }^{\mathrm{h}}$
}

College of Agronomy and Resources \& Environment; Tianjin Agricultural University, Tianjin 300384, China
aemail:547566053@qq.com, ${ }^{\mathrm{b}}$ email:1013658207@qq.com, ${ }^{\mathrm{c} e m a i l: 1627807654 @ q q . c o m},{ }^{\mathrm{d} e m a i l}:$

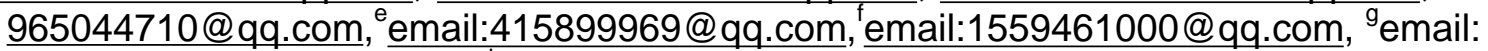

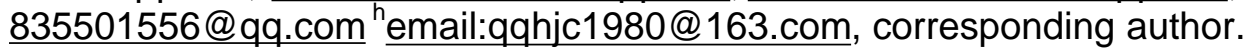

\begin{abstract}
Keywords: Microcystis aeruginosa; Flocculation; Microbial flocculant; alum; harvesting
Abstract: Microalgae harvesting was a bottleneck for controlling eutrophic waterbody and microalgal biofuel production, the combination of Microbial floculant (MBF) and alum was used to flocculate Microcystis aeruginosa in different conditions. The results showed that the combination of MBF and alum had a better flocculation on algae than that with the combination of MBF and other aluminum salts; the alum could aggregated algal cells to form small flocs by charge neutralization and MBF could link algal flocs together via netting and bridging action; the algal floc floated on the surface of solution which made it is easy to harvest.
\end{abstract}

\section{Introduction}

Cyanobacteria is one of the most primitive and ancient algae and it is widely distributed all over the world. Some dominant microalgae such as M. aeruginosa also blooms in rich nutrition waterbody in the summer, and a layer of turquoise and stench floating foam is formed, which is called "water bloom". Large-scale water bloom causes deterioration of water quality, sometimes it will consume dissolved oxygen of water and kill fish. Algae harvesting and removal not only purify the overlying water, but also will decrease phosphorus load in the sediment, so it plays a very important role in maintaining water ecological balance. Cyanobacteria is a kind of single-celled organisms and the volume is very small $(3-7 \mu \mathrm{m})$, so it is very difficult to harvest Cyanobacteria[1].

It has been reported that centrifugation, filtration and flocculation could concentrate algal suspension. Centrifugation is a kind of very effective method and it will not bring secondary pollution, which separates the algal cells and solution by centrifugal force, But centrifugation is not suitable for large-scale cultivation of microalgae for high cost[2]. Filtration is a common method for solid-liquid separation, but it is not suitable for harvesting microalgae cells because of their colloid stability and small volume[3]. Flocculation can aggregate small algal cells together and bring convenience for solid-liquid separation. Hydrolysis salt [4], clay minerals and modified clay minerals are usually used to flocculate microalgae cells[5]. Iron salts, aluminum salts and their polymers yield hydroxyl metal ions in aqueous solution for hydrolytic action. Positive charged hydroxyl metal ions can aggregate negative charged algal cells by charge neutralization, but iron and aluminum salts cause secondary pollution for residual of metal ions. Clay minerals are usually used to aggregate algae for their good adsorption and exchange ability, and they do not cause secondary pollution. Anderson [6] had pointed out that clay mineral is an economic and an effective method to remove the algae, and they have been successfully used in eutrophic aquaculture water. Pan Gang [7] studied the kinetics and mechanism of removing $M$. aeruginosa using 26 clay minerals, the best mineral was sepiolite among the different clay minerals, and its flocculation mechanism was bridging and netting. However, the algal flocs deposite at the bottom with clay minerals which make it difficult to harvest algae.

Our research has proved that microbial flocculant (MBF) had a good flocculation on $\mathrm{Fe}^{3+}, \mathrm{Fe}^{3+}$ and $\mathrm{MBF}$ form flocs and the flocculation mechanism is charge neutralization[8]. The combination of $\mathrm{MBF}$ and ferric chloride can flocculate $M$. aeruginosa, algal flocs float on the surface of solution 
which makes it is easy to harvest[9]. However, the $\mathrm{pH}$ of solution is low after flocculation, so the combination of alum and MBF is used to flocculate $M$. aeruginosa as alternative.

\section{Materials and methods}

\section{Materials}

M. aeruginosa (FACHB469) was purchased from the Freshwater Algae Culture Collection at the Institute of Hydrobiology, Chinese Academy of Sciences, which was cultured in BG11 medium at $24 \pm 1$ under and L:D=12:12 light-dark cycle with light intensity of $2200 \mathrm{LX}$. MBF was prepared according to the reported methods[9].

\section{Experimental methods}

\section{The flocculation effect of $M$. aeruginosa With the combination of MBF and different aluminum salts}

$200 \mathrm{~mL}$ M.aeruginosa culture $\left(\mathrm{OD}_{680}=1.513\right)$ was added into four conical flasks of $250 \mathrm{~mL}$ respectively, then the $\mathrm{pH}$ was adjusted to be about 5.2 with aluminum chloride, polyaluminum chloride and aluminum sulfate and alum. Then the flasks were put in the shaker for about 20min at temperature of $25^{\circ} \mathrm{C}$ and rotation of $140 \mathrm{rpm}$, then $5 \mathrm{~mL}$ MBF was added, mixed uniformly again at $25^{\circ} \mathrm{C}$ in the shaker( $140 \mathrm{rpm}$ ) for $5 \mathrm{~min}$ and allowed to stand for $20 \mathrm{~min}$ before being finally observed for the flocculation effect. At last, the transparent solution was sucked up by pipette and $\mathrm{OD}_{680}, \mathrm{pH}$, COD and TP were determined.

\section{Flocculation effect on M.aeruginosa with different dosage of MBF and alum}

$200 \mathrm{~mL}$ M. aeruginosa culture was added into 6 conical flasks $(250 \mathrm{~mL})$, alum solution $(1 \mathrm{~g} / \mathrm{L})$ was added into the solution to keep the $\mathrm{pH}$ of solution at about 5.2. Then the flasks were put in the shaker for $20 \mathrm{~min}$ at temperature of $25^{\circ} \mathrm{C}$ and rotation of $140 \mathrm{rpm}$, then different volume of $\mathrm{MBF}$ was added, mixed uniformly again at $25^{\circ} \mathrm{C}$ in the shaker(140 rpm) for $5 \mathrm{~min}$ and allowed to stand for 20 min before being finally observed for the flocculation effect. At last, the transparent solution was sucked up by pipette and $\mathrm{OD}_{680}, \mathrm{pH}, \mathrm{COD}$ and $\mathrm{TP}$ were determined.

\section{The effect of $\mathbf{p H}$ on the flocculation effect}

$200 \mathrm{~mL} M$. aeruginosa culture was added into 6 conical flasks $(250 \mathrm{~mL})$, the algal culture was adjusted to be different $\mathrm{pH}$ using alum solution $(1 \mathrm{~g} / \mathrm{L})$. The flasks were put in the shaker for $20 \mathrm{~min}$ at temperature of $25^{\circ} \mathrm{C}$ and rotation of $140 \mathrm{rpm}$, then $5 \mathrm{~mL}$ MBF was added, mixed uniformly again at $25^{\circ} \mathrm{C}$ in the shaker( $140 \mathrm{rpm}$ ) for $5 \mathrm{~min}$ and allowed to stand for $20 \mathrm{~min}$ before being finally observed for the flocculation effect. At last, the transparent solution was sucked up by pipette and $\mathrm{OD}_{680}, \mathrm{pH}$, COD and TP were determined.

\section{Detection methods}

Optical density $\left(\mathrm{OD}_{680 \mathrm{~nm}}\right)$ and $\mathrm{pH}$ are determined by UV-VIS spectrophotmeter(T6-1650E) and $\mathrm{pH}$ (FE28), $\mathrm{COD}_{\mathrm{Cr}}$ was measured by titration with acidic potassium and $\mathrm{TP}$ was determined by molybdenum antimony colorimetric method. Calculation method of removal of algae was based on the Li's method [1].

\section{Results and discussion}

\section{The flocculation effect of $M$. aeruginosa with the combination of MBF and different aluminum} salts

Fig. 1 showed that algal cells were small and dispersed uniformly in solution, so it was necessary to aggregate algal cells together before harvesting. The algal floc was small and precipitate at the bottom of solution with aluminum salts only. The combination of MBF and aluminum sulfate or alum showed a good flocculation on algal cells, algal cells aggregated together and floated on the surface of solution, and there was an clear interface between algal floc and solution. For the other flocculation, the algal floc was smaller and dispersed in the solution. Based on the point of size of floc 
and harvesting, the combination of $\mathrm{MBF}$ and aluminum sulfate or alum could give a good flocculation on M.aeruginosa.

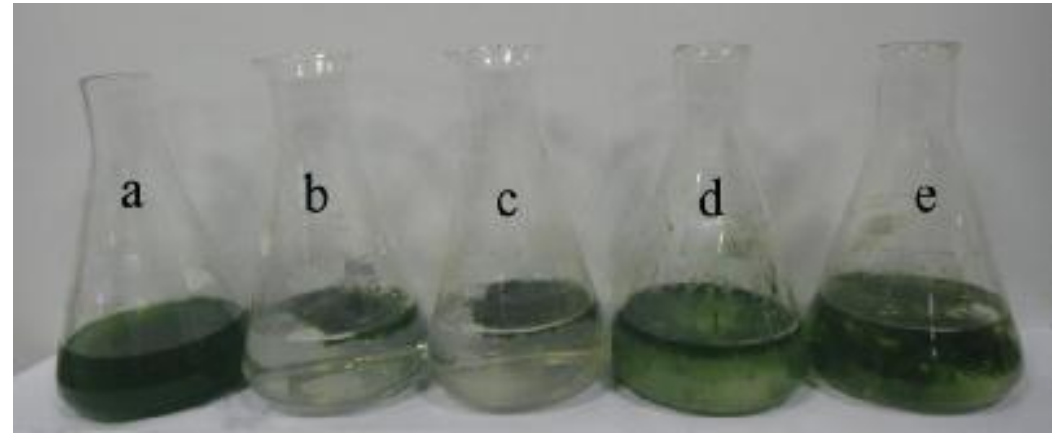

Fig. 1 The photoes of flocculation effect with combiantion of MBF and different aluminum salts(a: algal culture; $b$, $\mathrm{c}, \mathrm{d}, \mathrm{e}$ was combiantion of MBF and alum, aluminum sulfate, aluminum chloride and polyaluminum chloride )

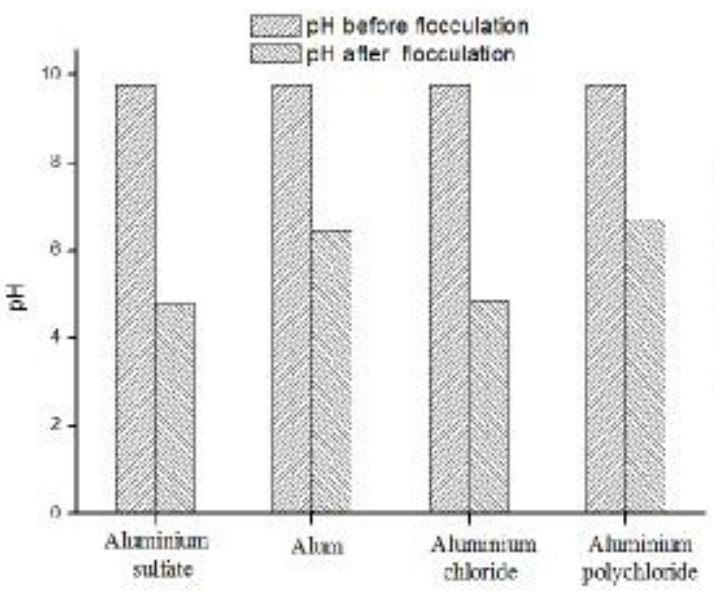

Fig.2 Change of $\mathrm{pH}$ before and after flocculation

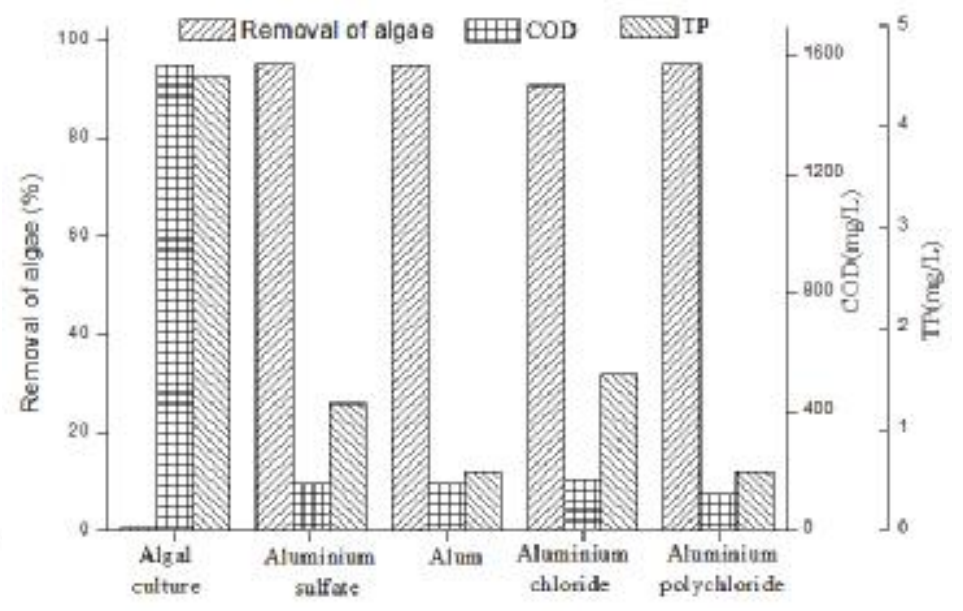

Fig.3 Remoal of algae, COD and TP Change of different treatments

Fig. 2 showed the change of $\mathrm{pH}$ before and after flocculation of $M$. aeruginosa. The hydrolysis of aluminum salts could produce positively charged hydroxyl aluminum ions and $\mathrm{H}^{+}$, positively charged hydroxyl aluminum ions aggregated negatively charged algal cells to form algal floc, $\mathrm{H}^{+}$could react with alkaline materials of culture which decreased $\mathrm{pH}$ of solution. The $\mathrm{pH}$ of culture was adjusted to be about 5.2 with aluminum salts, but $\mathrm{pH}$ of solution changed after adding MBF. The $\mathrm{pH}$ of solution was 6.45 and 6.71 respectively after flocculation with combination of MBF and alum and polyaluminum chloride, the $\mathrm{pH}$ of solution met the national discharged standard of sewage. The $\mathrm{pH}$ of solution was lower than 5.0 for the other two treatments which might have close relationship with bad flocculation. So the combination of $\mathrm{MBF}$ and alum was best flocculation method considering $\mathrm{pH}$ value of solution and flocculation effect.

Removal of algae was a key index to evaluate the flocculation effect. The removal of algae of four different treatments was higher than $90 \%$ (Fig.3), but the removal of algae could not tell you if it is easy to harvest. The removal of algae of the combination of MBF and polyaluminium chloride was $95.07 \%$, but the floc was smaller and dispersed, which brought difficulty for harvesting in the subsequent. The algae was cultured in the inorganic medium, so COD was an index to show the algal density, and COD was also the strict control index for the discharge of waste water, so COD of solution was determined. The COD of the original culture was the highest of $1567.68 \mathrm{mg} / \mathrm{L}$, the COD of the transparent water after flocculation was smaller and the removal of COD was higher than $90 \%$. Phosphorus was a limiting factor of algal growth, the total phosphorus concentration was lowest of $0.57 \mathrm{mg} / \mathrm{L}$ with the combination of MBF and alum. $M$. aeruginosa assimilated inorganic phosphorus and store in the cells, so algal cells harvesting was also a process to reomove phosphorus. 
The $\mathrm{pH}$ of $M$. aeruginosa culture was 9.79(Fig.4), the $\mathrm{pH}$ of solution was 5.20 and 2.40 respectively if the same amount of alum solution was added into same volume of $M$. aeruginosa culture and distilled water. The result showed that $\mathrm{H}^{+}$hydrolyzed by alum could react with alkaline materials of culture, decrease of $\mathrm{H}^{+}$accelerated hydrolysis of alum which made it easy to aggregate algal cells. The $\mathrm{pH}$ of solution increased from 5.94 to 6.46 with increase of MBF dosage, which showed the dosage of MBF had little influence on $\mathrm{pH}$ value of solution.

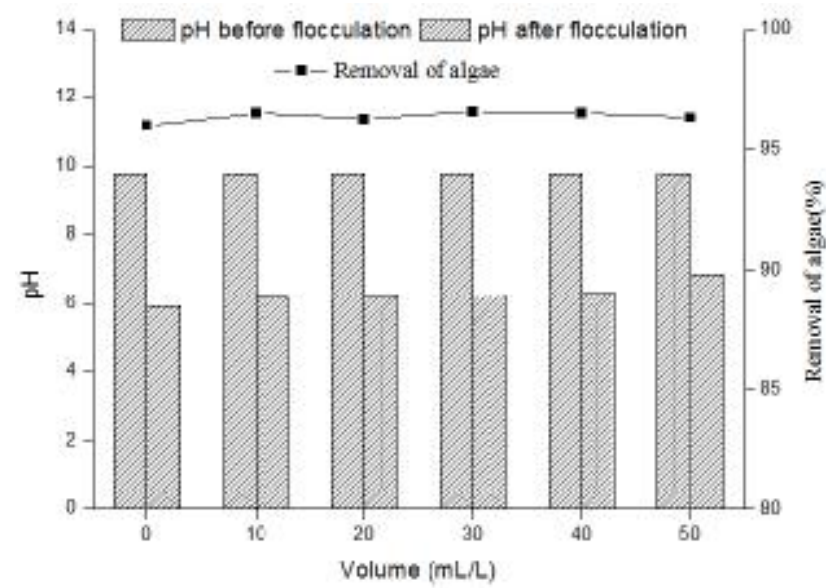

Fig.4 The change of $\mathrm{pH}$ and removal of algae with dosage of $\mathrm{MBF}$

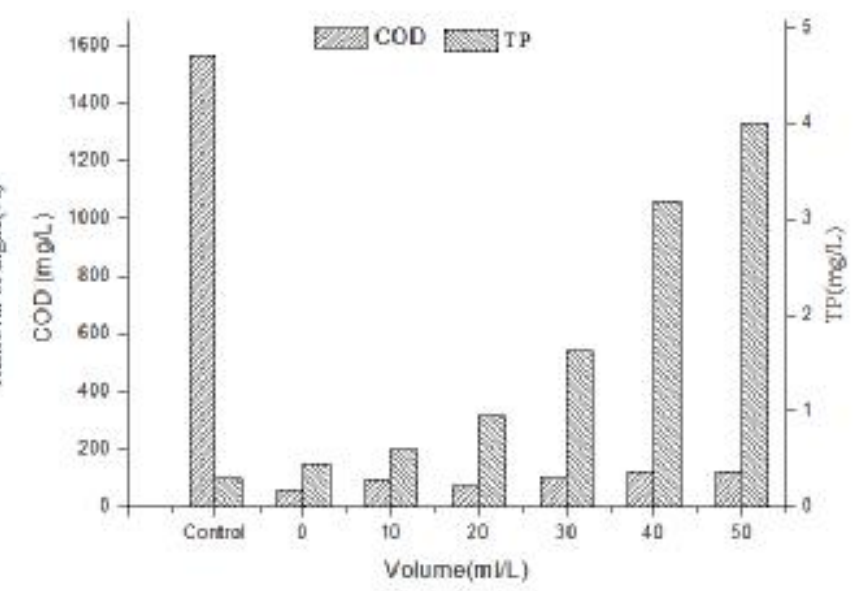

Fig.5 The change of COD and TP with dosage of $\mathrm{MBF}$

Fig.5 showed the change of COD and TP with dosage of MBF. Alum alone caould flocculate $M$. aeruginosa, the removal of algae was $95.97 \%$. However, algal flocs were small and precipitated at the bottom of the solution, so algal sludge was harvested by centrifugation. MBF could coagulate small flocs together to make it float on the surface of solution which made it is easy to harvest. Removal of algae had no sharp increase with the increase of MBF dose(Fig.4). MBF was an organic matter which caused residual of organic materials and phosphorus, so the COD and TP of the solution were determined in the subsequent.

The COD of the culture was $1567.68 \mathrm{mg} / \mathrm{L}$, and the COD of solution was lowest after flocculation with alum alone. Flocculation of algae with the combination of MBF and alum would increase COD of filtrate. However the COD of filtrate at dosage of $20 \mathrm{mg} / \mathrm{L}$ was lower than that of 10 $\mathrm{mg} / \mathrm{L}$, because low dosage of MBF did not aggregate all small algal flocs, so the optimum dosage of $\mathrm{MBF}$ was $20 \mathrm{mg} / \mathrm{L}$.

Phosphorus was a limited factor for growth of algae, it was also a strict control index for discharge of wastewater. The total phosphorus of algal culture was $4.60 \mathrm{mg} / \mathrm{L}$, and the total phosphorus of filtrate was $0.302 \mathrm{mg} / \mathrm{L}$ after removing algal cells, which indicated that growth of algae could assimilate a lot of phosphorus. The TP of filtrate after flocculation with alum alone was higher than filtrate after removing algal cells. The reason was that algae could adsorb phosphorus on the surface, this part of phosphorus released easily in acid environment. The total phosphorus increased sharply with increase of MBF, this part of phosphorus mainly came from MBF. Therefore, we must consider the dosage when MBF was used to treat wastewater, or else it would cause second pollution of COD and TP.

\section{The influence of $\mathrm{pH}$ on flocculation of $M$. Aeruginosa}

Fig. 6 showed the change of $\mathrm{pH}$ after flocculation and removal of algae with initial $\mathrm{pH}$. The $\mathrm{pH}$ of M. aeruginosa culture was 9.79. The algal culture was adjusted to be different $\mathrm{pH}$ using alum solution, and then $5 \mathrm{~mL} \mathrm{MBF}$ was added to aggregate small flocs together. The $\mathrm{pH}$ of solution changed a littler when initial $\mathrm{pH}$ was 4.02and 6.88. The removal of algae was was $95.91 \%$ at the $\mathrm{pH}$ of 4.07 , but the solution presented a little color of green, the reason was that the acid condition promoted the release of cytochrome. The removal of algae was low $(72.3 \%$ )at the $\mathrm{pH}$ of 6.88 . The removal of algae was high and the $\mathrm{pH}$ of solution increased when initial $\mathrm{pH}$ was 4.92 and 6.02, which proved that initial $\mathrm{pH}$ 
had an important influence on flocculation effect.

Fig. 7 showed the change of COD and TP with inital $\mathrm{pH}$. The COD of the culture was $1567.68 \mathrm{mg} / \mathrm{L}$. COD decreased and then increased with the increase of initial $\mathrm{pH}, \mathrm{COD}$ was the lowest at the $\mathrm{pH}$ of 6.02 . COD was the highest at the $\mathrm{pH}$ of 6.88 , because the removal of algae was low and some of the algae cells still remained in the filtrate. The variation trend of TP was the same with that of COD, TP was the lowest at the initial $\mathrm{pH}$ of 6.02. The above analysis shows that the COD and TP concentration after flocculation depended on whether the algal cells were completely removed. Therefore, algae harvesting not only harvested biomass of algae, but also it was a deep purification for wastewater containing algae.

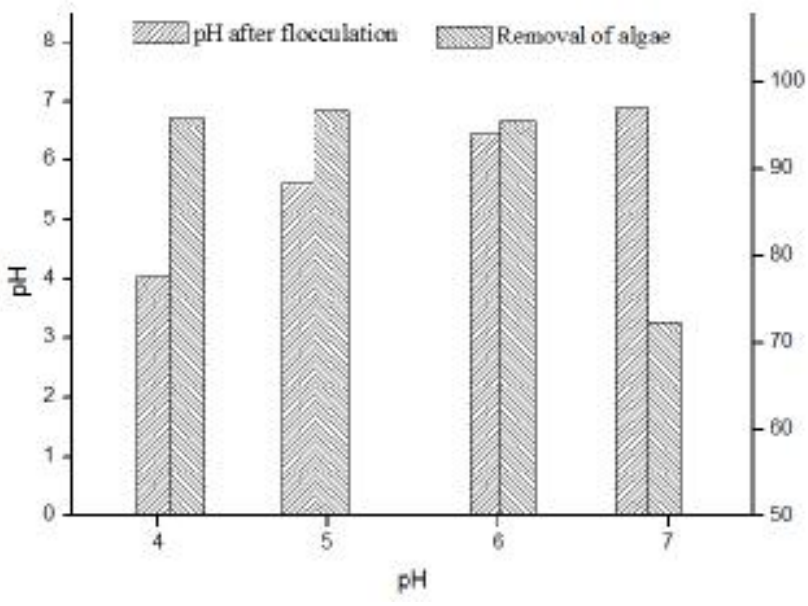

Fig.6 The change of $\mathrm{pH}$ and removal of algae with $\mathrm{pH}$

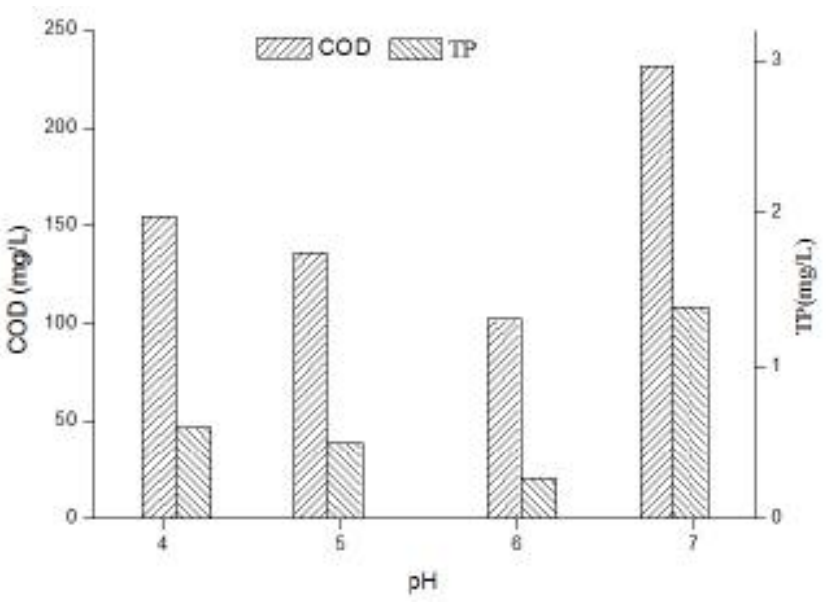

Fig.7 The change of COD and TP with $\mathrm{pH}$

\section{Conclusions}

The combination of alum and MBF had a good flocculation on $M$. aeruginosa, first the $\mathrm{pH}$ of culture was adjusted to be about 5.2 with alum solution, hydroxyl aluminum ions aggregated negatively charged algal cells to form smal algal flocs, then MBF $(20 \mathrm{ml} / \mathrm{L})$ was added to aggregate algal flcos together, and the algal floc floated on the surface of solution which made it is easy to harvest. Overuse of MBF had little impact on flocculation, but it would increase COD and TP of filtrate after flocculation. Alum solution addition cause decrease of $\mathrm{pH}$, it gave a good flocculation when $\mathrm{pH}$ was between 5 and 6 which showed $\mathrm{pH}$ had strong influence on flocculation.

\section{Acknowledgements}

This work was supported by Sience and Technology Innovation Foundation of national College Students (201410061091) and the National Key Research and Development Program of China (2016 YFD0800104) and Teaching Reform project(171006105E, 20170115).

\section{References}

[1] Y. Li, Y. Xu, T. Zheng and H.L. Wang: Bioresource Technology, Vol. 239 (2017),p.134.

[2] E.M. Grima, E.H. Belarbi, F.G.A. Fernandez , A.R. Medina: Biotechnology Advances, Vol. 20(2003), p. 491.

[3] C.Y. Chen, K.L. Yeh, R. Aisyah, D.J. Lee, J.S. Chang: Bioresource technology, Vol. 102(2011), p. 71.

[4] N. B. Wyatt, L. M. Gloe, P. V. Brady, J. C. Hewson: Biotechnollogy and Bioengineering, Vol. 102(2012), p.493.

[5] M.R. Sengco, D.M. Anderson: Journal of Eukaryotic Microbiology, Vol. 51(2004) , p.169.

[6] D.M. Anderson: Ocean \& coastal management, Vol. 52(2009) , p. 342.

[7] G. Pan, M.M. Zhang, H. Yan: Environmental Science(in chinese), Vol. 5(2003), p. 1. 
[8] J.C. Hao, Y.N. Deng, W.C. Cao,B. Lian and C.Q Liu: Chinese Journal of Environmental Engineering(in chinese), Vol. 5 (2011), p. 31507.

[9] J.C. Hao, B. Lian, R.B. Zhou, H.F. Liu, L.J. Shi, C.Q. Liu: Desalination \& Water Treatment, Vol. 57(2015), p. 20483. 